\title{
An air-drying model for piled logs of Eucalyptus globulus and Eucalyptus nitens in Chile
}

\author{
Horacio E. Bown ${ }^{1 *}$ (i) and Jean-Pierre Lasserre ${ }^{2}$
}

\begin{abstract}
Background: Water accounts for around half of the total mass in living trees, and therefore large savings can be achieved if logs are dried before transporting or burning.

Methods: An air-drying model for piled logs of Eucalyptus globulus Labill. and Eucalyptus nitens H.Deane \& Maiden was developed. Daily moisture content (MC) loss was modelled based on meteorological variables and pile characteristics. The trial had a factorial design with two species, two debarking treatments (with or without bark) and two log lengths (244 and 350 cm). Independent trials started in July 2007 (winter), October 2007 (spring) and January 2008 (summer). There were five replicate piles per season and treatment. Wood pile masses were weighted weekly or twice weekly using a crane, a 10,000 kg balance and chains to hold the piles.

Results: The main and interactive effects of seasons and treatments on daily MC loss were highly significant. However, the effect of season (climate) was far greater than the main effects of treatments or the season $x$ treatment interaction. Overall, E. globulus dried $20 \%$ faster than E. nitens, debarked logs dried $8 \%$ faster than barked logs and $244 \mathrm{~cm}$ logs dried $3 \%$ faster than $350 \mathrm{~cm}$ logs. Daily MC loss for the current day was better explained by a power function of $M C$ at the start of the day, daily air relative humidity, daily air temperature and the number of logs per square metre of pile cross-section (or an equivalent average log diameter).

Conclusions: The air-drying model for piled logs can be used to predict drying times (days) to achieve a given target moisture content, providing a new tool for decision-making in forest transport and industrial planning.
\end{abstract}

Keywords: Log air-drying model; Environmental variables; Eucalyptus; Management decisions

\section{Background}

Chile produces around 41 million cubic metres of timber each year from around 2.4 million ha of planted forests. Pinus radiata D.Don (1.470 million ha), Eucalyptus globulus Labill. (541,000 ha) and Eucalyptus nitens H.Deane \& Maiden (232,000 ha) are the most widely planted species (Instituto Forestal 2014). Pinus radiata is the main source for sawn timber and long fibre for the pulp industry, while E. globulus and E. nitens are the main providers of short fibre for pulp production, and marginal providers for veneer and other uses (Lignum 2005).

Chilean forest companies commonly dry large quantities of pulp logs at the roadside before being transported to pulp and paper plants, and recently to industrial boilers for the generation of steam, heat and

\footnotetext{
* Correspondence: hbown@uchile.cl

${ }^{1}$ Faculty of Forestry \& Conservation, University of Chile, P.O. Box 9206,

Santiago, Chile

Full list of author information is available at the end of the article
}

electricity. The rationale for this strategy is that water accounts for around half of the total mass in living trees, and therefore large savings in transport costs are achieved when logs are dried at the roadside. Also, industrial boilers require logs under a $50 \%$ moisture content on a dry basis (MC) to operate efficiently as the calorific power of wood increases as MC decreases. Moreover, yard handling would become unfeasible when considering drying and storing large log quantities for long periods of time.

Air-drying times vary widely from a couple of weeks to several months depending on species, dimensions, local weather conditions and time of year when the material is stacked (Simpson and Wang 2004). Rainfall, temperature, radiation and relative humidity all contribute to the wetting/drying process of wood piles. Also species exhibit a fivefold range in drying times, and water loss slows down as wood water content decreases 
(Simpson and Wang 2004). Additionally, different log diameters and lengths, debarking and piling specifications may strongly affect air-drying rates. Therefore, the aim of this study was to predict air-drying times for piled logs of E. globulus and E. nitens, specifically to (i) assess the influence of species, log diameter and length, and debarking on daily MC loss; (ii) correlate daily MC loss with meteorological variables; and (iii) discuss the possibility of applying such a model under different environmental conditions. The development of an air-drying model for piled logs may assist decision-makers in predicting drying times (days) to achieve a given target moisture content, and provide a new tool for decision-making in forest transport and industrial planning in Chile.

\section{Methods}

\section{Trial specification}

An experiment was set to determine MC loss of air-drying eucalypt wood piles in continental Concepción (Rucamanqui, latitude $37^{\circ} 15^{\prime} \mathrm{S}$ longitude $71^{\circ} 55^{\prime} \mathrm{W}$ ) in Chile. The climate is Mediterranean with cold wet winters and hot dry summers. Rainfall for the year 2007 was particularly low (696 mm) compared with the previous year $(1407 \mathrm{~mm})$. Annual air temperature for 2007 was on average $10.8{ }^{\circ} \mathrm{C}$, with a monthly minimum of $4.3{ }^{\circ} \mathrm{C}$ (June) and a monthly maximum of $19{ }^{\circ} \mathrm{C}$ (January). Rainfall in January and February 2008 was 10.1 and $7.3 \mathrm{~mm}$, respectively.

Piles were about $1.4 \mathrm{~m}$ wide, $1 \mathrm{~m}$ tall and either 2.44 or $3.50 \mathrm{~m}$ long. Treatments were made out of the combination of three factors: species (E. globulus or $E$. nitens), debarking (with bark or without bark) and length $(244$ or $350 \mathrm{~cm})$. Wood piles were stacked with freshly harvested logs (Fig. 1) at three dates: 14-July-2007 (winter), 6-October-2007 (spring) and 17-January-2008 (summer) and were measured for 167, 146 and 43 days, respectively. The total sample size was 120 piles ( 3 seasons $\times 2$ species $\times$ 2 debarking treatments $\times 2$ lengths $\times 5$ replicates).

For convenience, piles were grouped by length. Within each length, different combinations of species and debarking treatments were alternated. Piles were separated by poles anchored in the soil (Fig. 1a). Wood pile masses were weighed weekly or twice weekly using an electronic dynamometer with a capacity of 10 tonnes, hanging from a crane and towing ropes to hold the piles (Fig. 1b). Meteorological information was obtained from an automatic weather station located at a close distance from the piles.

\section{Data analysis}

All analyses were undertaken using The $\mathrm{R}$ System for Statistical Computing ( $\mathrm{R}$ Development Core Team, 2010). Variables were tested for normality and homogeneity of variance, and transformations were made as necessary to meet the underlying statistical assumptions of the models used. Analysis of variance (Proc GLM) was used to examine the main and interactive effects of species, lengths and debarking treatment on log moisture content loss. Analyses were conducted at the pile level. Tukey's least significant difference test was used to distinguish among individual means where applicable with a confidence level of $P \leq 0.05$. The effects of species, debarking treatments and lengths on slopes and intercepts of the linear relationship between average daily MC loss and number of logs per square metre

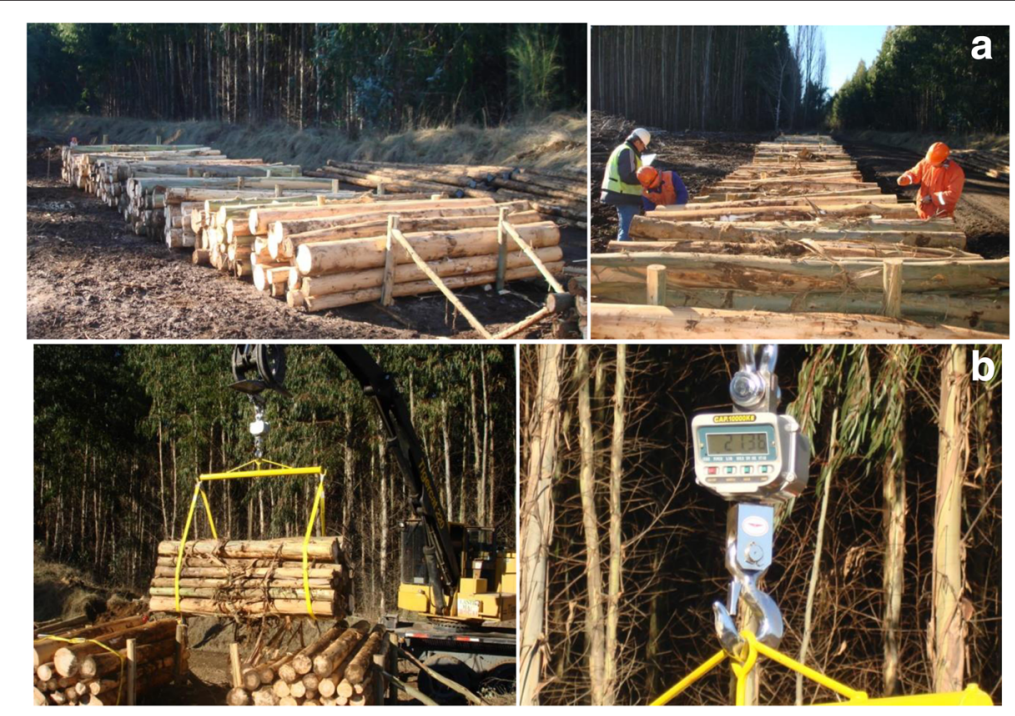

Fig. 1 a Layout of $\log$ piles of E. globulus and E. nitens set for the air-drying experiment. Piles were about $1.4 \mathrm{~m}$ wide, $1 \mathrm{~m}$ tall and $244 \mathrm{~cm}$ or $350 \mathrm{~cm}$ in length. Trials were started in winter, spring and summer with three factors: species (E. globulus, E. nitens), debarking (with bark, without bark) and length (2.44 m, $3.50 \mathrm{~m})$. b Detail of pile-weighing procedure and the dynamometer 
cross-section were tested for significance by analysis of covariance.

\section{Daily MC loss modelling}

Following Simpson and Wang (2004), daily moisture content (MC) loss $(\Delta M)$ per day (\% green basis) was modelled as

$$
\Delta M=a M^{b} T^{c} H^{d} N^{e}
$$

where $M$ is the $\mathrm{MC}$ at the beginning of the day (\%, green basis), $T$ is the daily average air temperature $\left({ }^{\circ} \mathrm{C}\right), H$ is the daily average air relative humidity (\%), $N$ is the number of logs per square metre cross-section and $a, b, c, d$ and $e$ are parameters to be determined by non-linear regression. Dummy variables were included in parameter " $a$ " of model (1) in order to account for the effect of species, debarking and log lengths, as: $a=\alpha_{0}+\alpha_{1} D_{1}$ $+\alpha_{2} D_{2}+\alpha_{3} D_{3}$, where $D_{1}, D_{2}, D_{3}$ are dummy variables representing species $(0=E$. globulus, $1=E$. nitens $)$, debarking $(0=$ without bark, $1=$ with bark $)$ and lengths $(0=244 \mathrm{~cm}, 1=350 \mathrm{~cm})$, respectively; and $\alpha_{0}, \alpha_{1}, \alpha_{2}$ and $\alpha_{3}$ are parameters to be determined by non-linear regression.

\section{Results}

\section{Treatment effects}

There were inherent treatment differences in pile volume and mass when first stacked. When freshly stacked, $\log$ piles ranged from 1748 to $4299 \mathrm{~kg}, 2.7$ to $6.2 \mathrm{~m}^{3}$ cord (stacked) volume, 1.6 to $3.9 \mathrm{~m}^{3}$ solid volume and 9

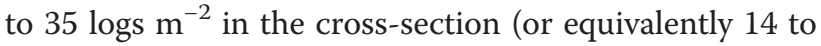
$33 \mathrm{~cm}$ in average log diameter) (Table 1). The initial wood moisture content ranged from 47 to $60 \%$ (average $54.3 \%$ ) on a green basis ( 89 to $149 \%$ on a dry basis, average $119.6 \%)$. Basic wood density ( \pm 1 standard error, $n=30)$ was significantly greater for $E$. globulus (514 \pm $\left.6 \mathrm{~kg} \mathrm{~m}^{-3}\right)$ than E. nitens $\left(491 \pm 5 \mathrm{~kg} \mathrm{~m}^{-3}, P=0.003\right)$.

Log moisture content generally decreased over time in all piles across seasons, species, lengths and debarking treatments. Moisture content loss over time for piles of either E. globulus or E. nitens $(350 \mathrm{~cm} \log$ lengths/with bark) stacked in summer, spring and winter are shown in Fig. 2. Other log lengths and debarking treatments followed the same pattern as the one illustrated in Fig. 2. Log MC decreased for both species at higher rates for logs stacked in summer than spring than winter (summer $>$ spring $>$ winter). Also, log MC decreased at decreasing rates as logs became drier for piles stacked in summer and spring (faster at the beginning and slower as time progressed). In contrast, moisture content of logs stacked in winter decreased slowly while weather was cold and damp to decrease at increasing rates as weather conditions improved (Table 1, Fig. 2). Overall, E. globulus dried faster than $E$. nitens.

The main effects of season $\left(F_{2,95}=456-1769\right)$ on daily $\log \mathrm{MC}$ loss were far greater than the main effects of treatment $\left(F_{7,95}=15-62\right)$ or their interaction $\left(F_{14,95}=7-29\right)$, as shown by their $F$ values and $P$ range (Table 1 ). Daily log $\mathrm{MC}$ loss was on average threefold greater for piles stacked in summer $(0.53 \%$ per day, green) than in winter $(0.17 \%$ per day, green), while two times greater in summer than in spring $(0.25 \%$ per day, green). In contrast, the treatment effects were relatively small compared to season: $E$. globulus dried 3-47 \% (average $20 \%$ ) faster than E. nitens, debarking increased the drying rate by 3-12\% (average $8 \%$ ) and logs $244 \mathrm{~cm}$ long dried 1-4 \% (average $3 \%$ ) faster than logs $350 \mathrm{~cm}$ long (Table 1).

Because log diameter (or the number of logs per square metre in the pile cross-section) had such a strong influence on the wood moisture content loss per day, covariance analysis was carried out to separate the effects of the covariate, log diameter or number, $\left(F_{1,100}=60, P<0.001\right)$ from the effect of the factors (species, lengths, debarking, seasons). Slopes $\left(F_{2,100}=3.8, P=0.02\right)$ but not intercepts $\left(F_{2,100}=2.9, P=\right.$ $0.06)$ of the linear relationship between daily MC loss and the number of logs per square metre in the pile crosssection were significantly influenced by season (Fig. 3). Slopes and intercepts of these linear relationships were not influenced by species, lengths or debarking treatments when tested within each season $\left(F_{7,100}=0.9-1.3\right.$, $P>0.28$ ). However, it is worth noting that for summer, $E$. nitens showed an insignificantly yet lower slope than E. globulus (Fig. 3).

\section{Air-drying model}

Model (1) was fitted to the experimental data of daily $\mathrm{MC}$ loss on a green $\left(\Delta M_{\text {green }}\right)$ and dry basis $\left(\Delta M_{\mathrm{dry}}\right)$. The general model for $\Delta M_{\text {green }}$ was:

$$
\begin{aligned}
\Delta M_{\text {green }}= & a_{\text {green }} M_{\text {green }}^{2.3999} T^{0.2268} H^{-5.6734} N^{0.7987} \\
& r^{2}=0.67, \quad P<0.001
\end{aligned}
$$

with

$$
a_{\text {green }}=119020-26671 D_{1}-40969 D_{2}-6814 D_{3}
$$

where $M$ is the $\mathrm{MC}$ at the beginning of the day (\%, green basis), $T$ is the daily average air temperature $\left({ }^{\circ} \mathrm{C}\right), \mathrm{H}$ is the daily average air relative humidity (\%) and $N$ is the number of logs per square metre crosssection. Dummy variables were included in parameter " $a$ " of model (1) in order to account for the effect of species, debarking and log lengths, as: $a=\alpha_{0}+\alpha_{1} D_{1}+$ $\alpha_{2} D_{2}+\alpha_{3} D_{3}$, where $D_{1}, D_{2}, D_{3}$ are dummy variables representing species $(0=E$. globulus, $1=E$. nitens $)$, debarking 
Table 1 Initial and final condition of air-drying log piles $(n=120)$ of $E$. nitens and E. globulus in two lengths $(244 \mathrm{~cm}, 350 \mathrm{~cm})$ with and without bark in Rucamanqui, Los Angeles, Chile

\begin{tabular}{|c|c|c|c|c|c|c|c|c|c|c|c|}
\hline Season & Species & Treatment & $n$ & Days & $\begin{array}{l}\text { Green mass } \\
\text { start }(\mathrm{kg})\end{array}$ & Water loss (kg) & $\begin{array}{l}\text { Water loss } \\
\left(\mathrm{kg} \mathrm{day}^{-1}\right)\end{array}$ & $\begin{array}{l}\text { Total MC loss } \\
(\%, \text { green) }\end{array}$ & 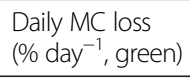 & $\begin{array}{l}\text { Total MC } \\
\text { loss }(\%, d r y)\end{array}$ & $\begin{array}{l}\text { Daily MC loss } \\
\left(\% \text { day }^{-1}, \text { dry) }\right.\end{array}$ \\
\hline \multirow[t]{9}{*}{ Winter } & \multirow[t]{4}{*}{ E. nitens } & 244 bark & 5 & 167 & $1950 \pm 71 e$ & $529 \pm 16 d$ & $3.2 \pm 0.1 d$ & $27.2 \pm 0.4 b c$ & $0.16 \pm 0.003 b c$ & $62.9 \pm 0.7 a$ & $0.38 \pm 0.004 a$ \\
\hline & & 244 debark & 5 & 167 & $2172 \pm 115$ de & $608 \pm 39 c d$ & $3.6 \pm 0.2 \mathrm{~cd}$ & $27.9 \pm 0.6 b c$ & $0.17 \pm 0.004 b c$ & $59.8 \pm 1.2 \mathrm{a}$ & $0.36 \pm 0.007 a$ \\
\hline & & 350 bark & 5 & 167 & $2848 \pm 103 b c$ & $658 \pm 20 c d$ & $3.9 \pm 0.1 \mathrm{~cd}$ & $23.1 \pm 0.5 d$ & $0.14 \pm 0.003 d$ & $50.8 \pm 1.4 b$ & $0.30 \pm 0.008 b$ \\
\hline & & 350 debark & 5 & 167 & $2534 \pm 171 \mathrm{~cd}$ & $693 \pm 49 c$ & $4.1 \pm 0.3 c$ & $27.4 \pm 0.6 b c$ & $0.16 \pm 0.003 b c$ & $57.8 \pm 1.1 \mathrm{ab}$ & $0.35 \pm 0.006 a b$ \\
\hline & \multirow[t]{5}{*}{ E. globulus } & 244 bark & 5 & 167 & $2387 \pm 68$ cde & $641 \pm 15 c d$ & $3.8 \pm 0.1 \mathrm{~cd}$ & $26.9 \pm 0.6 c$ & $0.16 \pm 0.003 c$ & $63.0 \pm 1.6 a$ & $0.38 \pm 0.009 a$ \\
\hline & & 244 debark & 5 & 167 & $2751 \pm 42 c$ & $877 \pm 19 b$ & $5.3 \pm 0.1 b$ & $31.9 \pm 1.1 \mathrm{a}$ & $0.19 \pm 0.006 a$ & $69.0 \pm 2.9 a$ & $0.41 \pm 0.018 a$ \\
\hline & & 350 bark & 5 & 167 & $3225 \pm 123 a b$ & $899 \pm 31 b$ & $5.4 \pm 0.2 b$ & $28.0 \pm 1.1 \mathrm{bc}$ & $0.17 \pm 0.006 b c$ & $64.5 \pm 2.8 \mathrm{a}$ & $0.39 \pm 0.017 a$ \\
\hline & & 350 debark & 5 & 167 & $3435 \pm 70 a$ & $1051 \pm 41 a$ & $6.3 \pm 0.2 a$ & $30.6 \pm 0.9 a b$ & $0.18 \pm 0.005 a b$ & $65.6 \pm 2.3 a$ & $0.39 \pm 0.014 a$ \\
\hline & & Mean & 40 & & $2663 \pm 83$ & $744 \pm 28$ & $4.5 \pm 0.2$ & $27.9 \pm 0.5$ & $0.17 \pm 0.003$ & $61.7 \pm 1.0$ & $0.37 \pm 0.006$ \\
\hline \multirow[t]{9}{*}{ Spring } & \multirow[t]{4}{*}{ E. nitens } & 244 bark & 5 & 146 & $2526 \pm 81 d$ & $993 \pm 30$ cde & $6.8 \pm 0.2 \mathrm{cde}$ & $39.4 \pm 0.8 a b$ & $0.27 \pm 0.005 a b$ & $93.7 \pm 1.8 \mathrm{a}$ & $0.64 \pm 0.012 a$ \\
\hline & & 244 debark & 5 & 146 & $2942 \pm 100 \mathrm{~cd}$ & $958 \pm 36$ de & $6.6 \pm 0.2 \mathrm{de}$ & $32.6 \pm 0.5 \mathrm{~cd}$ & $0.22 \pm 0.004 \mathrm{~cd}$ & $73.1 \pm 1.7 \mathrm{c}$ & $0.50 \pm 0.012 c$ \\
\hline & & 350 bark & 5 & 146 & $3796 \pm 152 a$ & $1178 \pm 65 b c$ & $8.1 \pm 0.4 b c$ & $31.1 \pm 1.3 d$ & $0.21 \pm 0.009 d$ & $73.0 \pm 2.8 \mathrm{c}$ & $0.50 \pm 0.019 c$ \\
\hline & & 350 debark & 5 & 146 & $3761 \pm 112 a$ & $1506 \pm 57 a$ & $10.3 \pm 0.4 a$ & $40.1 \pm 1.2 \mathrm{a}$ & $0.27 \pm 0.008 a$ & $85.1 \pm 2.4 a b$ & $0.58 \pm 0.016 a b$ \\
\hline & \multirow[t]{5}{*}{ E. globulus } & 244 bark & 5 & 146 & $2487 \pm 102 d$ & $912 \pm 22 e$ & $6.2 \pm 0.2 e$ & $36.8 \pm 0.9 a b$ & $0.25 \pm 0.006 a b$ & $86.2 \pm 1.7 \mathrm{bc}$ & $0.59 \pm 0.012 b c$ \\
\hline & & 244 debark & 5 & 146 & $2668 \pm 92 \mathrm{~cd}$ & $992 \pm 25$ cde & $6.8 \pm 0.2 \mathrm{cde}$ & $37.2 \pm 0.6 a b$ & $0.26 \pm 0.004 a b$ & $80.5 \pm 1.4 b c$ & $0.55 \pm 0.010 \mathrm{bc}$ \\
\hline & & 350 bark & 5 & 146 & $3133 \pm 67 b c$ & $1119 \pm 30 \mathrm{~cd}$ & $7.7 \pm 0.2 \mathrm{~cd}$ & $35.7 \pm 0.4 b c$ & $0.24 \pm 0.002 b c$ & $84.4 \pm 1.7 \mathrm{bc}$ & $0.58 \pm 0.011 \mathrm{bc}$ \\
\hline & & 350 debark & 5 & 146 & $3577 \pm 192 a b$ & $1330 \pm 65 \mathrm{ab}$ & $9.1 \pm 0.4 a b$ & $37.2 \pm 0.5 a b$ & $0.25 \pm 0.003 \mathrm{ab}$ & $77.8 \pm 2.7 c$ & $0.53 \pm 0.018 c$ \\
\hline & & Mean & 40 & & $3111 \pm 90$ & $1124 \pm 34$ & $7.7 \pm 0.2$ & $36.3 \pm 0.5$ & $0.25 \pm 0.004$ & $81.7 \pm 1.2$ & $0.56 \pm 0.009$ \\
\hline \multirow[t]{9}{*}{ Summer } & \multirow[t]{4}{*}{ E. nitens } & 244 bark & 5 & 43 & $2537 \pm 124 b$ & $466 \pm 31 d$ & $10.8 \pm 0.7 d$ & $18.3 \pm 0.5 d$ & $0.43 \pm 0.012 d$ & $41.1 \pm 1.4 \mathrm{c}$ & $0.96 \pm 0.032 c$ \\
\hline & & 244 debark & 5 & 43 & $2468 \pm 30 b$ & $463 \pm 17 d$ & $10.8 \pm 0.4 d$ & $18.8 \pm 0.6 d$ & $0.44 \pm 0.015 d$ & $39.1 \pm 1.5 c$ & $0.91 \pm 0.036 c$ \\
\hline & & 350 bark & 5 & 43 & $3296 \pm 85 a$ & $593 \pm 26 c$ & $13.8 \pm 0.6 c$ & $18.0 \pm 0.4 d$ & $0.42 \pm 0.008 d$ & $39.9 \pm 0.6 c$ & $0.93 \pm 0.014 c$ \\
\hline & & 350 debark & 5 & 43 & $3373 \pm 174 a$ & $635 \pm 24 b c$ & $14.8 \pm 0.6 b c$ & $18.9 \pm 0.5 d$ & $0.44 \pm 0.013 d$ & $38.9 \pm 1.4 c$ & $0.91 \pm 0.033 c$ \\
\hline & \multirow[t]{5}{*}{ E. globulus } & 244 bark & 5 & 43 & $2261 \pm 56 b$ & $593 \pm 5 c$ & $13.8 \pm 0.1 \mathrm{c}$ & $26.3 \pm 0.5 b c$ & $0.61 \pm 0.011 b c$ & $59.8 \pm 1.3 a$ & $1.39 \pm 0.030 a$ \\
\hline & & 244 debark & 5 & 43 & $2445 \pm 62 b$ & $727 \pm 19 b$ & $16.9 \pm 0.5 b$ & $29.7 \pm 0.4 a$ & $0.69 \pm 0.009 a$ & $58.7 \pm 1.0 \mathrm{ab}$ & $1.37 \pm 0.023 a b$ \\
\hline & & 350 bark & 5 & 43 & $3035 \pm 104 a$ & $753 \pm 28 b$ & $17.5 \pm 0.6 b$ & $24.8 \pm 0.6 c$ & $0.58 \pm 0.013 c$ & $53.0 \pm 1.5 b$ & $1.23 \pm 0.035 b$ \\
\hline & & 350 debark & 5 & 43 & $3233 \pm 148 a$ & $900 \pm 43 a$ & $20.9 \pm 1.0 a$ & $27.8 \pm 0.3 a b$ & $0.65 \pm 0.008 a b$ & $53.8 \pm 1.0 b$ & $1.25 \pm 0.023 b$ \\
\hline & & Mean & 40 & & $2831 \pm 76$ & $641 \pm 24$ & $14.9 \pm 0.6$ & $22.8 \pm 0.7$ & $0.53 \pm 0.017$ & $48.1 \pm 1.4$ & $1.12 \pm 0.033$ \\
\hline ANOVA/ & Covariate & & & & - & $* *$ & $* *$ & $* * *$ & $* * *$ & $* * *$ & $* * *$ \\
\hline \multirow[t]{3}{*}{ ANCOVA } & $S$ & & & & $* * *$ & $* * *$ & $* * *$ & $* * *$ & $* * *$ & $* * *$ & $* * *$ \\
\hline & T & & & & $* * *$ & $* * *$ & $* * *$ & $* * *$ & $* * *$ & $* * *$ & $* * *$ \\
\hline & $S \times T$ & & & & $* * *$ & $* * *$ & $* * *$ & $* * *$ & $* * *$ & $* * *$ & $* * *$ \\
\hline
\end{tabular}

Main and interactive effects of season (S) and treatment (T) were assessed by analysis of variance and covariance. The covariate was the number of logs per square metre in the pile cross-section. Significant differences are presented as $n s$ non-significant, ${ }^{*}$ significant at $P<0.05$, and ${ }^{* * *}$ significant at $P<0.001$. Values are presented as means $( \pm 1$ SE) for seasons and treatments. Separation of means was determined by a Tukey test when applicable. Different letters indicate significant differences at $P<0.05$

$(0=$ without bark, $1=$ with bark $)$ and lengths $(0=244 \mathrm{~cm}$, $1=350 \mathrm{~cm})$, respectively.

The relationship between average log diameter, $d$, and number of logs per square metre of pile cross-section, $N$, $\left(d=14.4182+45.1968 \mathrm{e}^{-0.12 N}, r^{2}=0.91, P<0.001\right)$ can be replaced into (1) if $d$ rather than $N$ is preferred to be used in the calculations.

Model (1) was also fitted to predict daily MC loss on a dry basis $\left(\Delta M_{\text {dry }}\right)$ as

$$
\begin{aligned}
\Delta \mathrm{M}_{d r y} & =\mathrm{a}_{d r y} \mathrm{M}_{d r y}^{2.3570} \mathrm{~T}^{0.2460} \mathrm{H}^{-5.7448} \mathrm{~N}^{0.8422}, \mathrm{r}^{2} \\
& =0.63, \quad \mathrm{P}<0.001
\end{aligned}
$$

with

$$
a_{d r y}=55319-10470 D_{1}-22015 D_{2}-3641 D_{3}
$$

There was an observed upper bound of moisture content loss $\left(\Delta M_{\text {green }}\right)$ of $1.97 \%$ per day on a green basis 


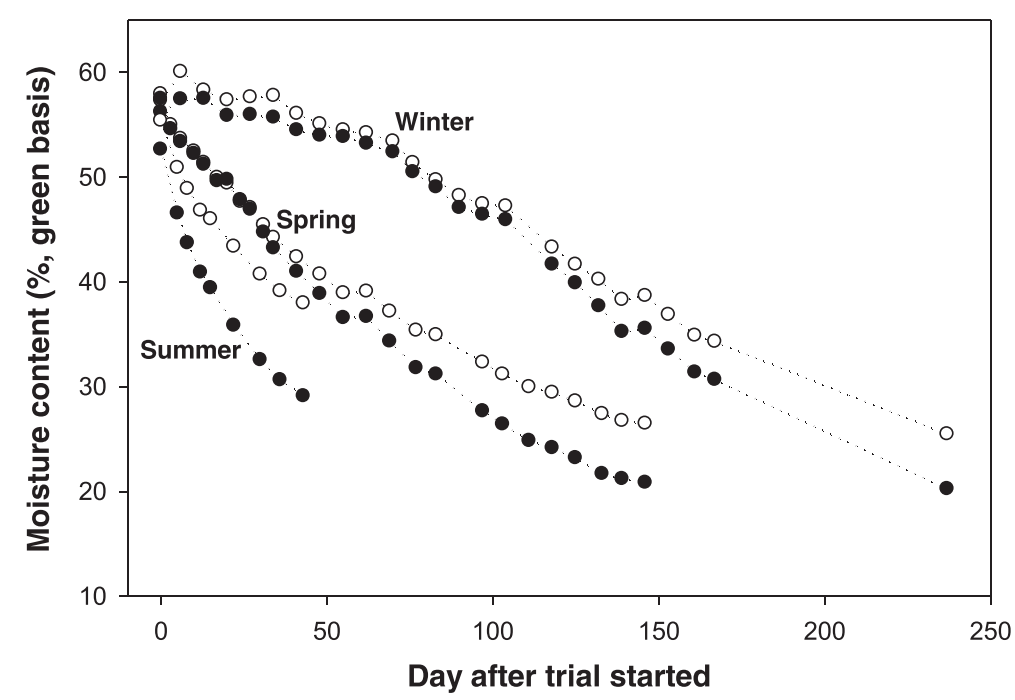

Fig. 2 Changes in wood moisture content (\%, green basis) for six randomly selected $350 \mathrm{~cm}$ logs piles with bark. Open symbols represent $E$. nitens while closed symbols represent $E$. globulus

(3.96 \% per day on a dry basis) given by the experimental data that should be acknowledged within the model. In practice, this means than any estimate over this value should be set to $1.97 \%$ (3.96\% dry basis), and this upper bound would be required to ensure that realistic values of daily MC loss are estimated.

The model was apparently unbiased for a traditional residual analysis (Fig. 4 a) and also when predicting moisture content for each log pile for the duration of the experiment (Fig. 4 b). Rainfall was uncorrelated with the log moisture content loss.

Air-drying times for E. globulus and E. nitens with and without bark are shown in Fig. 5. The graph shows estimated times (days) to reduce the moisture content on a green basis from 60 to 50, 60 to 40,60 to 30 and 60 to $20 \%$, for logs stacked in any day of the year. One important observation is that piles stacked in late summer and early autumn had greatly extended drying times,

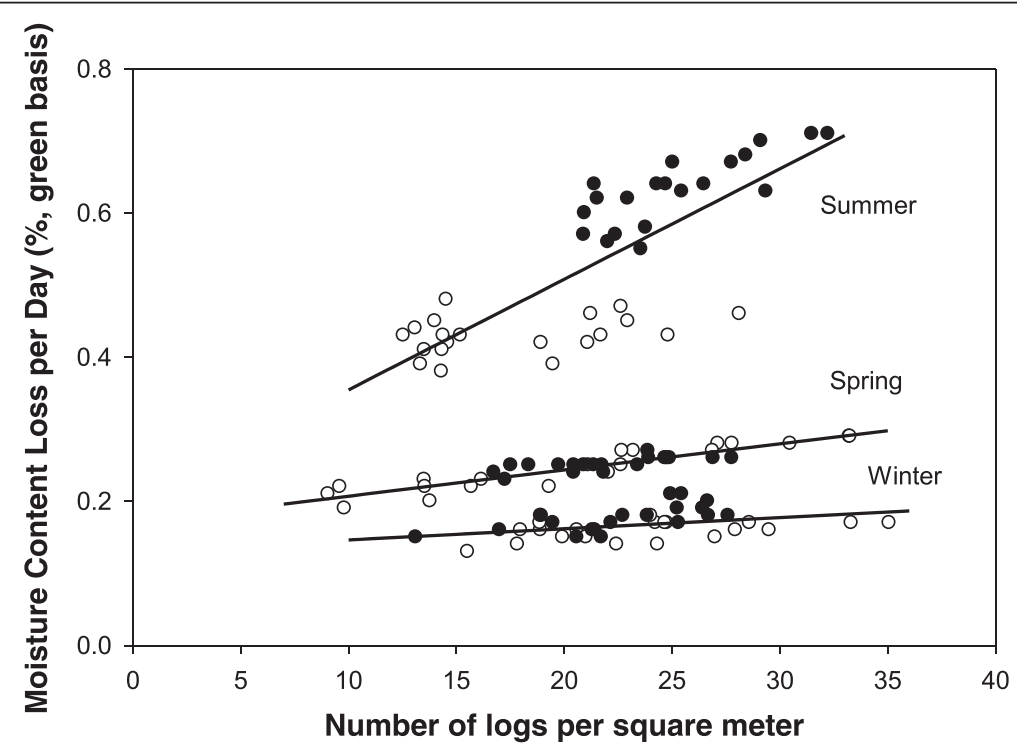

Fig. 3 The linear relationship between average log moisture content loss per day (\%, green basis) and the number of logs per square metre in the pile cross-section. Analysis of covariance showed that slopes, but not intercepts, of these linear relationships were influenced by the season in which the piles were stacked. Various treatments (species, lengths, debarking) did not have any significant influence on these linear relationships. Logs stacked in summer, $y=0.20140+0.01534 x, r^{2}=0.61, P<0.001$; spring, $y=0.17089+0.00363 x, r^{2}=0.85, P<0.001 ;$ winter, $y=0.13097+$ $0.00155 x, r^{2}=0.16, P<0.01$. Open symbols represent $E$. nitens while closed symbols represent $E$. globulus 


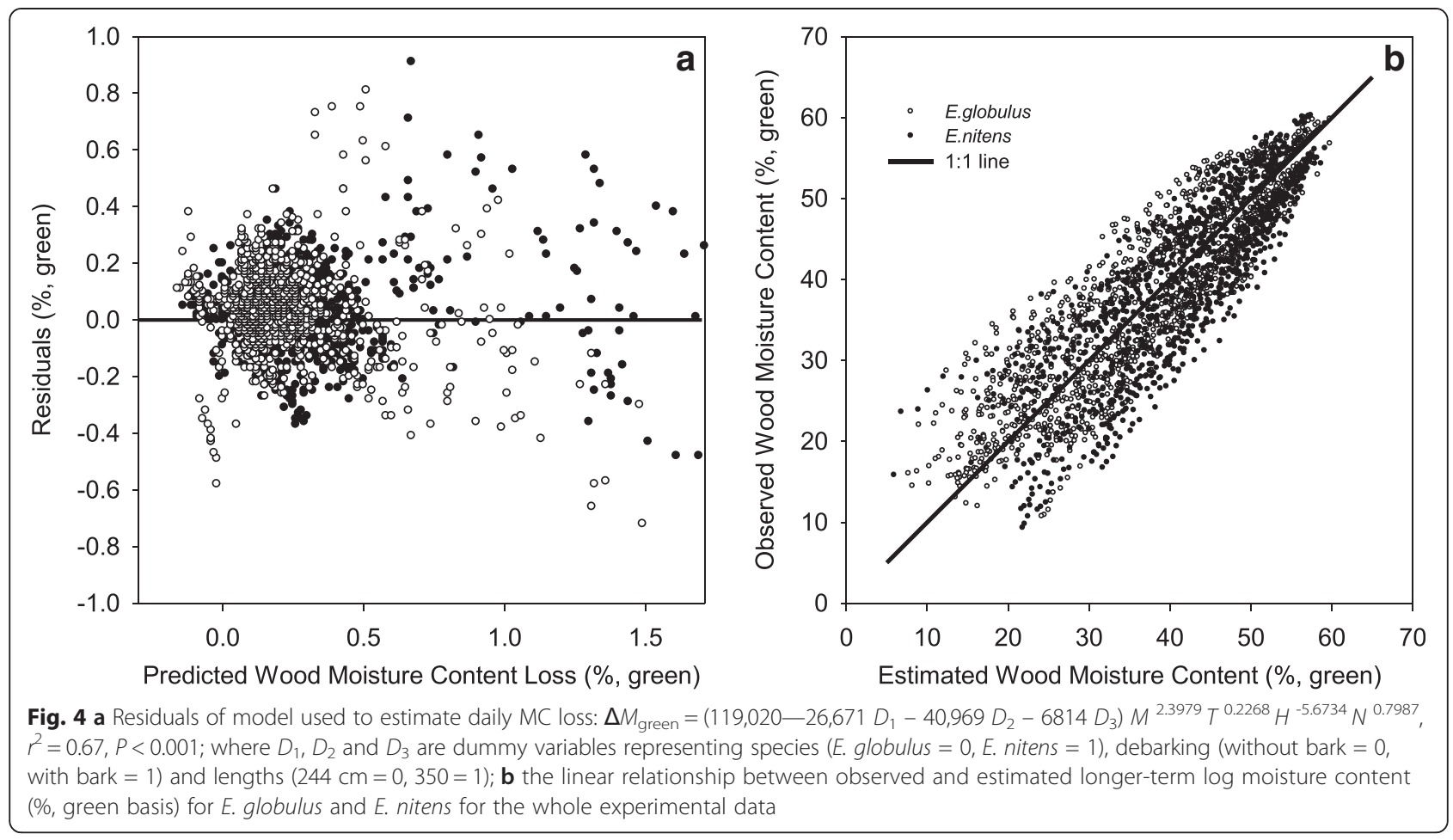

particularly for low target moisture contents (20-30\%, green basis). In contrast, piles stacked in late spring to early summer required the least drying times compared with other stacking dates.

The influence of log diameter (or the number of logs per square metre of cross-section) on the air-drying time of E. globulus logs $(244 \mathrm{~cm})$ with bark is shown in Fig. 6 a. For instance, for logs stacked in May, a 30 \% reduction in green moisture content would be achieved in 206 days for an average log diameter of $18 \mathrm{~cm}\left(22 \operatorname{logs} \mathrm{m}^{-2}\right)$, and this period would increase by 70 days for average log diameters of $30 \mathrm{~cm}\left(9 \operatorname{logs~} \mathrm{m}^{-2}\right)$. Air-drying time was also strongly influenced by initial log moisture content for E. globulus (Fig. 6b). For instance, for logs stacked in April, a $30 \%$ reduction in green moisture content would be achieved in 218, 248 and 290 days starting with initial wood moisture contents of 60, 55 and $50 \%$ (green basis), respectively. A similar pattern was observed for the air-drying time of $E$. nitens $\operatorname{logs}(244 \mathrm{~cm})$ with bark in relation to either log diameter (or the number of logs per square metre of cross-section) (Fig. 6c) or initial log moisture content (Fig. 6d), although with extended drying times compared to E. globulus.

\section{Discussion}

Drying times of Eucalyptus logs can vary up to eightfold depending on weather conditions. Such large time variation poses tremendous uncertainty in flow planning and quality control (Simpson and Wang 2004). Additionally, moisture content has an impact on transport costs and bioenergy yields, and therefore accurately determining airdrying times becomes critical for minimising costs and maximising returns. As expected, there is a clear seasonal effect with logs drying faster when stacked in late spring to early summer than in late summer to early autumn, which can be explained by observed values of air relative humidity and temperature being the main environmental drivers of log moisture content loss. Although climate (season) was the main drive of log moisture content loss, there were also important effects of species and debarking treatments on this variable. E. globulus dried on average $20 \%$ faster than $E$. nitens, and debarking enhanced moisture content loss by $8 \%$. For instance, in order to reduce $20 \%$, the moisture content on a green basis, E. globulus logs, with bark, harvested/stacked in January would take 22 days compared to 29 for E. nitens. Similarly, debarking would reduce drying times from 22 to 17 days in E. globulus and from 29 to 20 days in E. nitens to achieve a $20 \%$ reduction in moisture content for piles freshly harvested/ stacked in January. Visser et al. (2014) also found faster drying of debarked logs of $P$. radiata, suggesting that radial water movements are a significant contributor to the log drying process. Log lengths did not have a significant effect on moisture content loss in our study, although 244-cm logs dried on average $3 \%$ faster than 350-cm logs.

Generally, species with low-density wood dry faster than higher density ones (Simpson and Hart 2001). However, the opposite result was found in the current study. E. globulus (which has a basic wood density of $514 \mathrm{~kg} \mathrm{~m}^{-3}$ ) dried on average $20 \%$ faster than E. nitens, 


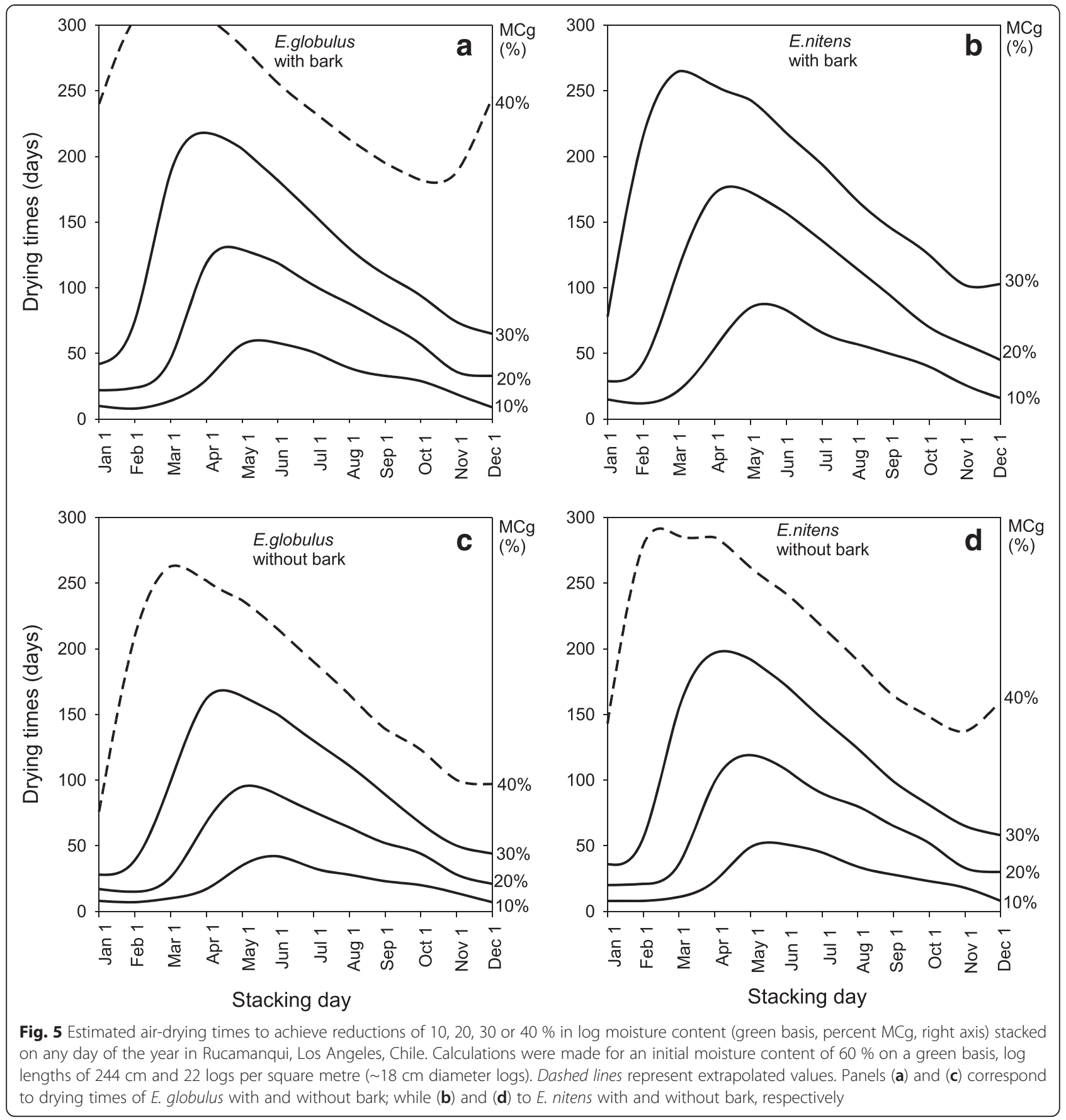

(which has a $5 \%$ lower basic density $\left(491 \mathrm{~kg} \mathrm{~m}^{-3}\right)$ ). This result may indicate that water movement is more related to fibre conductivity than wood density. Muneri and Raymond (2001) reported that E. globulus exhibits greater fibre length and coarseness than $E$. nitens which may point in such direction.

The daily MC loss decreased at decreasing rates as the $\log$ MC dropped. For instance, logs of E. globulus with bark would take 22, 26 and 35 days in order to reduce $20 \%$ moisture content starting with and initial wood moisture content of 60,55 and $50 \%$ on a green basis, respectively (provided they are stacked in January). Log diameter also showed to have a strong influence on drying times, e.g. $20 \%$ reductions in moisture content in $18 \mathrm{~cm}$ logs would take 22 days if stacked in January, and that time would almost double for $30 \mathrm{~cm}$ logs. A similar pattern was observed for E. nitens. This was also observed by Visser et al. (2014), for $P$. radiata logs, arguing that smaller diameter logs and split logs exhibit a larger surface area to mass ratio and a smaller distance water 


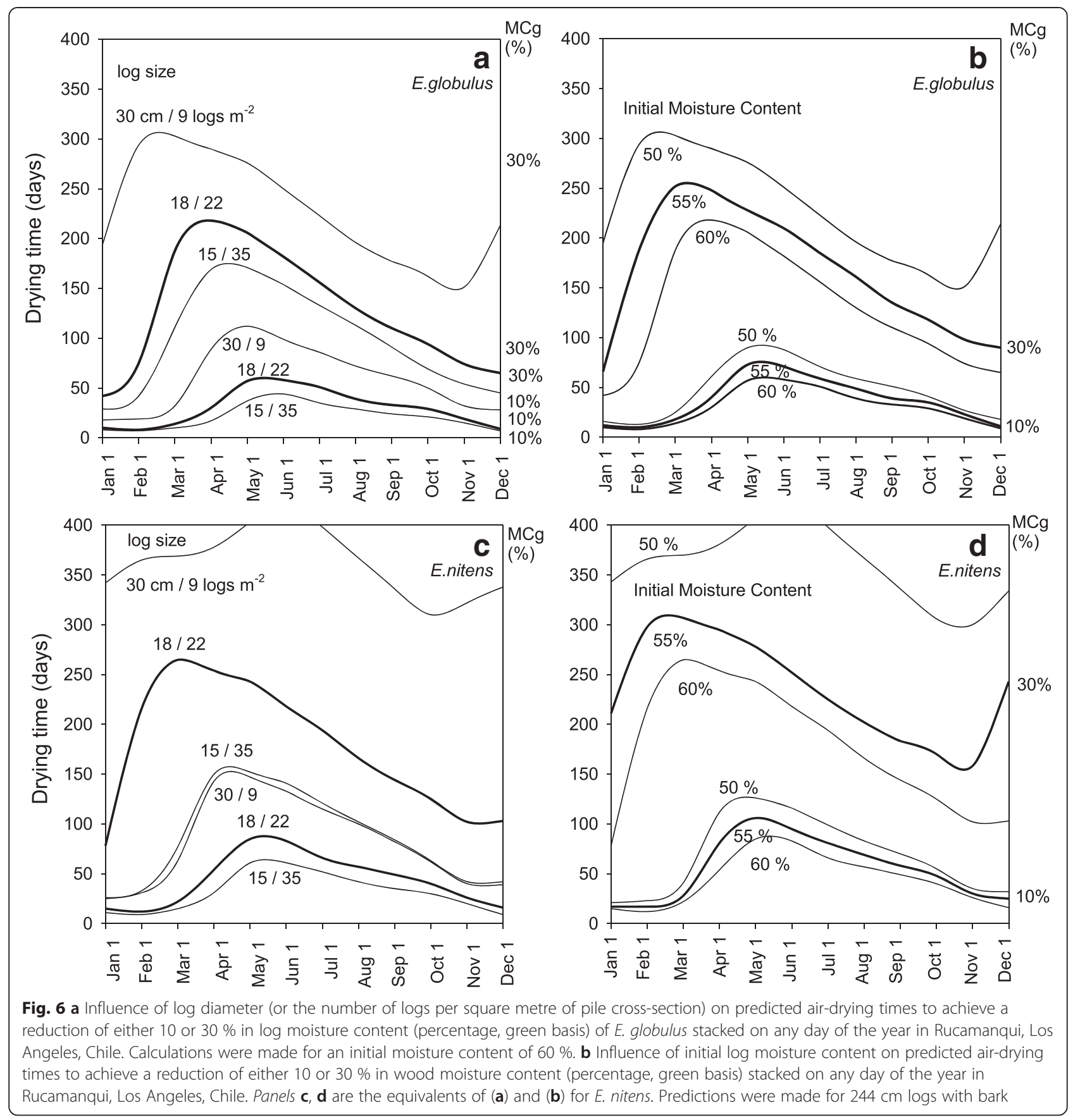

must move from the inner log to the surface in order to evaporate. Since wood-free water flows primarily along the stem evaporating form the log ends (Walker 2006), there must be a secondary movement across the stem if small diameter logs, large split logs and debarked logs dry faster than large whole logs (Abbot et al. 1997, Visser et al. 2014).

Daily MC loss $(\Delta M)$ scaled positively following a power function with the $\mathrm{MC}$ at the beginning of the day $(M)$, average air temperature $(T)$ and the number of logs per square metre in the cross-section $(N)$, and scaled negatively with air relative humidity $(H)$. Simpson and Wang (2004) found the same variables to significantly explain daily MC loss, but found that a power model fitted best Ponderosa pine (Pinus ponderosa Douglas ex C.Lawson) while a linear model was most suitable for Douglas-fir (Pseudotsuga menziesii (Mirb.) Franco). Rietz (1970) considered also wind speed and rainfall to explain air-drying rates of lumber. Surprisingly, in our study, rainfall was uncorrelated to air-drying rates, which we 
assumed was explained because most water intercepted by the piles was evaporated, while only marginal amounts of water infiltrated the logs.

Intensively tended forest plantations of E. globulus and E. nitens in Chile provide biomass for the short- fibre pulp industry and more recently for industrial boilers for the generation of electricity and heat. The companies are looking to reduce the moisture content of the wood in order to diminish the transport cost of pulp logs and to increase the energy power of the biomass. Kiln-drying would be largely uneconomical because of large log diameters (long residence times) and low log prices not justifying high kiln-drying costs. Hence, air-drying becomes the natural alternative to kiln-drying for fuelwood (Filbakk et al. 2011). However, air-drying times are known to vary largely from several weeks to several months depending on species, dimensions, local weather conditions and time of year when the material is stacked (Simpson and Wang 2004). Most studies on air-drying times are based on stacked lumber, and only a few, notably Simpson and Wang (2004), have determined air-drying times for logs, and to the best of our knowledge none has worked with logs of Eucalyptus species.

The model fitted for E. globulus and E. nitens in the current study may be potentially applied to other sites provided that some validation can be obtained. This approach was the same originally developed by Simpson and Hart (2001), who applied a model fitted for only a few locations to many climates across the USA. Once underlying processes describing air-drying rates are explained by environmental variables, then we may correctly assume that the same processes would explain changes for other climates. Reinforcing this idea, Filbakk et al. (2011) found that air-drying rates of whole trees of broadleaved species at three sites in Norway were mainly explained by air temperature and precipitation independent of site. The simplicity of the model developed in this study, based on four variables only, may provide guidance to decision-makers in the forestry industry to minimise transport costs based on currently available meteorological data. This is something that managers may consider since moisture content has an impact on transport costs and energy yields. The model is now routinely used by Forestal Mininco S.A. to predict log air-drying times at the roadside across different environmental conditions.

\section{Conclusions}

In summary, the effect of season (climate) was far greater than the effect of species, debarking or log length on log moisture content loss. Overall, E. globulus dried $20 \%$ faster than E. nitens, debarked logs dried $8 \%$ faster than barked logs and $244 \mathrm{~cm}$ logs dried $3 \%$ faster than $350 \mathrm{~cm}$ logs. Daily MC loss was explained by a power model of MC at the beginning of the day, average daily air temperature, average daily air relative humidity and the number of logs per square metre cross-section of the piles (or equivalently average log diameter). The model needs an upper bound of $1.97 \%$ daily MC loss on a green basis (3.96 \% on a dry basis). The model can be used to estimate air-drying times of piles stacked any day of the year, to any final $\mathrm{MC}$, for a wide range of log diameters (in the approximate 14- to 33- $\mathrm{cm}$ range), and for different environmental conditions; providing a new tool for decision-making in forest transport and industrial planning.

\section{Competing interests}

The authors declare that they have no competing interests.

\section{Authors' contributions}

Both JPL and HEB designed the experiment, monitored data collection and did intial data analysis. JPL wrote material and methods and substantially contributed in other sections of the manuscript. HEB made figures and tables and wrote the introduction, results and discussion. All authors have read and approved the final manuscript.

\section{Acknowledgements}

This research was sponsored by Forestal Mininco S.A. The experiments and measurements undertaken for this paper comply with the current laws of Chile. None of the authors have any competing interests in the manuscript.

\section{Author details}

${ }^{1}$ Faculty of Forestry \& Conservation, University of Chile, P.O. Box 9206, Santiago, Chile. ${ }^{2}$ Forestal Mininco S.A., Los Canelos 71, San Pedro, Concepción, Chile.

Received: 16 June 2015 Accepted: 1 September 2015 Published online: 05 October 2015

\section{References}

Abbot, P, Lowore, J, Khofi, C, \& Werren, M. (1997). Defining firewood quality: a comparison of quantitative and rapid appraisal techniques to evaluate firewood species from a Southern African savanna. Biomass \& Bioenergy, 12, 429-437.

Filbakk, T, Høibø, O, \& Nurmi, J. (2011). Modelling natural drying efficiency in covered and uncovered piles of whole broadleaf trees for energy use. Biomass and Bioenergy, 35, 454-463.

Instituto Forestal. (2014). Anuario Forestal 2014. [Technical Report]. Boletín Estadístico No 144 (p. 159). Concepción: Instituto Forestal. http://wef.infor.cl/ publicaciones/publicaciones.php. Access date: August 23, 2015.

Lignum. (2005, April). Eucalyptus nitens, Nueva Especie Latifoliada Industrial. Revista Lignum.

Muneri, A, \& Raymond, CA. (2001). Nondestructive sampling of Eucalyptus globulus and E. nitens for wood properties; II. Fibre length and coarseness. Wood Science and Technology, 35, 41-56.

Rietz, RC. (1970). Air drying lumber in a forklift yard. [USDA forest service research note Fpl-0209]. Madison, WI, USA: US Department of Agriculture, Forest Service Forest Products Laboratory.

Simpson, WT, \& Hart, CA. (2001). Method for estimating air-drying times of lumber. Forest Products Journal, 51(11/12), 56-63.

Simpson, WT, \& Wang, X. (2004). Estimating air-drying times of small-diameter ponderosa pine and Douglas-fir logs. Forest Products Journal, 54(12), 24-28.

Visser, R, Berkett, H, \& Spinelli, R. (2014). Determining the effect of storage conditions on the natural drying of radiata pine logs for energy. New Zealand Journal of Forestry Science, 44: 3.

Walker, J. (2006). Primary wood processing (2nd ed.). Dordrecht, Netherlands: Springer Verlag. 